\author{
SERIES 'CHEST PHYSIOTHERAPY' \\ Edited by $S$. Hill \\ Number 2 in this series
}

\title{
Physiotherapy and bronchial mucus transport
}

\author{
C.P. van der Schans* ${ }^{+}$, D.S. Postma**, G.H. Koëter**, B.K. Rubin ${ }^{\S}$
}

\begin{abstract}
Physiotherapy and bronchial mucus transport. C.P. van der Schans, D.S. Postma, G.H. Koëter, B.K. Rubin. (C) ERS Journals Ltd 1999.

ABSTRACT: Cough and expectoration of mucus are the best-known symptoms in patients with pulmonary disease. The most applied intervention for these symptoms is the use of chest physiotherapy to increase bronchial mucus transport and reduce retention of mucus in the airways. Chest physiotherapy interventions can be evaluated using different outcome variables, such as bronchial mucus transport measurement, measurement of the amount of expectorated mucus, pulmonary function, medication use, frequency of exacerbation and quality of life.

Measurement of the transport rate of mucus in the airways using a radioactive tracer appears to be an appropriate outcome variable for short-term studies. Evaluation of chest physiotherapy only with pulmonary function tests appears to be inadequate in short-term studies. The popularity of using pulmonary function tests is probably based more on the availability of the instruments than on a theoretical basis related to the question of chest physiotherapy improving mucus transport. Quality of life and progression of the disease are not often used as outcome variables, but it may be worthwhile to use these in the future.

Eur Respir J 1999; 13: 1477-1486.
\end{abstract}

\begin{abstract}
*Dept of Rehabilitation University Hospital, Groningen, and ${ }^{+}$Pulmonary Rehabilitation Centre Beatrixoord, Haren, the Netherlands. **Dept of Pulmonary Medicine University Hospital, Groningen, the Netherlands. ${ }^{\text {Bowman Gray School of }}$ Medicine, Winston-Salem, USA.
\end{abstract}

Correspondence: C.P. van der Schans, University Hospital Groningen, Dept of Rehabilitation, Hanzeplein 1, PO Box 30. 001, 9700 RB Groningen, the Netherlands. Fax: 31503619243

Keywords: Chest physiotherapy, hospitalization, mucus, pulmonary function, quality of life, radioactive tracer clearance

Received: March 191998

Accepted after revision November 71998
Healthy human lungs are protected against inhaled dust particles and micro-organisms by the continuous production of mucus and the transport of deposited particles and mucus to the oropharynx. In patients with diseases of the airways, hypersecretion and expectoration of mucus are common symptoms. Although these symptoms are wellknown they are poorly defined. In normal conditions, the production of mucus in the airways is estimated to be between $10-100 \mathrm{~mL} \cdot$ day $^{-1}$. This wide range is probably the result of the fact that it is impossible to measure mucus production under normal conditions. A clear definition of hypersecretion appears impossible until the normal quantity of mucus is known. Another approach could be to use the symptom itself as a definition, for instance, hypersecretion is defined when there is expectoration of mucus during a given period. Neither definition takes into account the complexity of the problem. In patients with airways disease there is often a combination of hypersecretion and impaired transport. Hypersecretion can be caused by the production of inflammatory mediators with chronic infection increasing the number of mucous glands and the output from secretory cells and glands. Transport of mucus is impaired because of cilial damage, inhibition of or uncoordinated cilial movement, or due to unfavourable rheological conditions of the mucus. The imbalance between transport and secretion may lead to stasis of the mucus in the airways, expectoration of mucus, or both.
The consequences of stasis of the mucus in the airways are poorly understood. It is generally assumed that stasis of mucus in the lower airways contributes to airway obstruction. However there are very few data supporting this hypothesis. Expectoration of mucus does not necessarily mean that there is also stasis of mucus. The results of AIKAWA et al. [1] demonstrate that chronic obstructive pulmonary disease (COPD) patients with emphysema have very little stasis of mucus in their airways, although they had a history of expectoration. This is consistent with the results of a study by the authors in which spontaneous mucus transport was found to be higher in chronic bronchitis patients than in emphysema patients [2]. The effects of stasis of mucus on pulmonary function may vary because of differences in the quantity and localization of mucus in the airways. Severe mucus plugging in the peripheral airways may have an effect on lung volume, such as the residual volume (RV)/total lung capacity (TLC) ratio or trapped gas volume. A smaller amount of mucus, not completely obstructing the airway, may have an affect on forced expiratory flow variables.

It is also assumed that stasis of mucus may predispose to the development of pulmonary infections, cause pathological changes in the lungs [3], contribute to decline in pulmonary function [4], and death from lung disease [5]. However, it is not clear whether hypersecretion is "just" a marker of inflammation or a cause for pathological

Previous articles in this series: No. 1: E. Houtmeyers, R. Gosselink, G. Gayan-Ramirez, M. Decramer. Regulation of mucociliary clearance in health and disease. Eur Respir J 1999; 13: 1177-1188. 
changes. There is even some evidence that stasis of mucus protects against inhaled material. KING et al. [6] investigated the response to methacholine in dogs by infusion and inhalation. The ratio between the "infusion response", and the "inhaled response" was calculated and plotted against the thickness of the mucus layer. The study found that in dogs with more hypersecretion and a thicker mucus layer, the inhaled methacholine response was less. This suggests that a thicker mucus layer with more hypersecretion protects against inhaled material.

It is often stated that chronic expectoration of mucus is a socially disabling symptoms. This seems very likely, but data supporting this statement could not be found.

Treatment of mucus retention includes pharmacotherapy and the application of chest physiotherapy [7]. The pharmacotherapy of mucus clearance disorders is discussed in a separate article in this series. Many methods used by physiotherapists, including breathing exercises, manual percussion and postural drainage, have been used since the beginning of this century [8]. Application of these techniques through the years is based upon the clinical impression of physiotherapist and physicians, the subjective experience of the patient that they have beneficial effects, and to the lack of alternative methods to treat mucus retention. More recently, new physiotherapeutic interventions, such as the forced expiration technique (FET) more commonly called the active cycle of breathing technique (ACBT), positive-end expiratory pressure (PEEP) breathing, and flutter breathing have been introduced as alternatives or adjuncts to the conventional methods.

It can be difficult to judge the relative efficacy of the different components of chest physiotherapy in the treatment of mucus retention. These usually consist of a combination of different techniques. There are no simple measurements that reliably reflect changes in mucus transport. It has been shown that chest physiotherapeutic methods that may be effective in the care of one type of patient can be harmful in others $[9,10]$. This is consistent with the clinical impression that patients with various airway diseases respond differently to chest physiotherapy, perhaps because of differences in the underlying pathology and physiology.

\section{Short review of methods}

\section{Evaluation of mucus clearance techniques}

Chest physiotherapy can be defined as the external application of a combination of forces to increase mucus transport. The techniques, intensity, duration and frequency are different between physiotherapists in different parts of the world, and have changed over the years. This makes comparison of results or experiences difficult unless the techniques are described in detail. Chest physiotherapy has been evaluated using measurements of airflow, changes in gas exchange, measurements of pulmonary mucus clearance, and measuring the volume of expectorated mucus. These evaluation techniques range from methods that are complex and difficult to perform but reproducible and quite accurate for short-term studies (e.g. the clearance of radiolabelled particles from the airway), to very simple methods that produce results that are next to meaningless (e.g. measurements of expectorated sputum volume in chronic lung disease).

\section{Comparisons of various physiotherapeutic techniques}

\section{Chest physiotherapy}

Chest physiotherapy to improve mucus transport can consist of different manoeuvres, including special breathing techniques, percussion or vibration and postural drainage, all with or without directed coughing. This combination of techniques is sometimes called postural drainage. The authors prefer to reserve this latter term for the specific gravity-assisted positions discussed later in this article. Other techniques to augment mucus clearance include the use of special devices such as PEEP masks, flutter valves or high frequency chest wall or airway oscillation devices.

In healthy dogs, it was found that percussion combined with postural drainage increased tracheal mucus transport velocity [11]. When compared to a control intervention, chest physiotherapy improved mucus transport in stable patients with COPD [12]. When compared to coughing, the results are conflicting, with investigators finding an improvement of mucus transport during chest physiotherapy when compared to coughing in patients with COPD or bronchorrhea [13, 14], but not cystic fibrosis (CF) [15]. Differences in application duration and differences in the disease pathophysiology are probably partly responsible for these different outcomes.

Pulmonary function tests or measurements of gas exchange have also been used to evaluate the effects of chest physiotherapy [16-32]. Some of these studies were able to detect an improvement in pulmonary function tests or gas exchange after physiotherapy in patients with COPD [19, $20,23]$ and in patients with $\mathrm{CF}[17,23,24]$ and that patients with CF and COPD respond equally well [23]. Other studies have not demonstrated an improvement in pulmonary function after physiotherapy in patients with COPD $[18,29,33]$ or CF $[25,31,34]$. In many studies, relatively small groups of patients are included, and this increases the risk of a type II error. Some studies have also suggested undesirable side-effects of chest physiotherapy on pulmonary function and gas exchange, e.g. increased airway obstruction and desaturation in COPD patients [18] and in acutely ill patients [32]. There seems to be no beneficial effect of chest physiotherapy on the time to recovery during an acute exacerbation of COPD $[16,21]$ or to the resolution of pneumonia $[22,35]$.

In summary, chest physiotherapy is probably effective in improving mucus transport, but the effects on pulmonary function are conflicting, probably because the impact of mucus retention on pulmonary function varies in different patients. Further studies are needed to identify the patients or circumstances which are at risk from complications or adverse effects of chest physiotherapy.

\section{Percussion, vibration and high frequency oscillation}

Manual percussion and vibration techniques are probably the best-known, but also the least uniformly applied techniques of chest physiotherapy. The rationale behind these techniques is not clear. The effects may be based on shear thinning of secretions, "squeezing" secretions from distal airways with changes in intrathoracic pressures, 
formation of central mucus globules that are easier to expectorate, freeing the adhesive secretions from the airway walls or the induction of coughs. Manual percussion is performed with cupped hands on the ventral, lateral, and dorsal side of the thorax of the patient with a frequency of approximately 3-6 Hz. Mechanical vibration is performed with higher frequencies, up to $40 \mathrm{~Hz}$. Percussion and vibration are applied during both exhalation and inspiration, or during expiration only. Oscillation of air in the airways is also thought to improve mucus transport. Intrapulmonary oscillatory airflow can be induced directly by oscillation of the air at the mouth or indirectly by oscillation of the thorax using special devices.

The effect of these techniques has been evaluated using measurements of mucus transport [36-46]. In patients with COPD, vibration with a frequency of $41 \mathrm{~Hz}$ and an amplitude of $2 \mathrm{~mm}$ did not affect mucus transport [36]. In a mixed group of patients with hypersecretion, percussion did not affect mucus transport [37]. In COPD patients, manual percussion had a small effect on mucus transport [38]. The effect on mucus transport appears to be frequency dependent [39-43]. In animal studies, a frequency of $12-15 \mathrm{~Hz}$ was most effective in improving tracheal mucus transport $[39,40]$. In an experimental mode, a frequency of $13 \mathrm{~Hz}$ also appeared to be the most effective frequency in improving mucus transport [41]. However, in another animal study a frequency between 25 and 35 $\mathrm{Hz}$ appeared to be the most effective [43]. A frequency of $\sim 10-15 \mathrm{~Hz}$, which is outside the range of the manual techniques but lower then most commercial vibrators, appears to have the best effect on mucus transport [40]. This is consistent with the finding that in CF patients, the intrathoracic pressures induced by vibration, and thus the vibration induced expiratory flows, appeared to be frequency dependent [42]. The direction of the induced flow is also important. Based on the results of experimental studies it can be concluded that the oscillation/vibration should lead to an expiratory biased flow, i.e. a higher expiratory than inspiratory flow [41, 46-48] particularly when there is increased mucus rigidity [41].

Studies have failed to demonstrate any additional increase in mucus transport when vibration was added to chest physiotherapy in patients with COPD or CF [37, 38, $49,50]$, although one study found an improvement of the "rate of expectoration of mucus" when vibration was added to chest physiotherapy [51]. The combination of percussion and postural drainage may be more effective, in terms of the volume of expectorated mucus, than coughing alone in patients with COPD [52]. High frequency oscillations and chest physiotherapy are equally effective in terms of the volume of expectorated mucus [53].

On their own, percussion and vibration techniques may improve pulmonary function and gas exchange in patients with CF [54]. These effects could result from improved mucus transport, but effects independent of changes in mucus transport have been described. Improved gas exchange by high frequency oscillation may also be the result of changes in breathing pattern as described by PiQueT et al. [55]. In a long-term study, WARWICK and HANSEN [56] demonstrated an improvement in forced vital capacity (FVC) and forced expiratory volume in one second (FEV1) during a period of treatment with high frequency chest wall compression compared with a period during which conventional chest physiotherapy was applied without this intervention in patients with CF. ARENS et al. [57] found no differences between chest physiotherapy and high frequency oscillation on the thorax in $\mathrm{CF}$ patients during an exacerbation on pulmonary function and clinical status.

Side-effects of these interventions, such as an increase in airflow obstruction, have also been described in patients with COPD $[18,58]$. In an animal study, the application of vibration and percussion was associated with the development of atelectasis [59].

There are insufficient data to justify the routine use of percussion, vibration or oscillation techniques when added to chest physiotherapy. The experimental results of high frequency oscillation are quite promising. Nevertheless controlled clinical studies are needed to investigate the effect on mucus transport and to clarify under which circumstances or in which type of patient this technique would be most effective, as well as which patients are at risk of adverse effects from these interventions.

\section{Postural drainage}

The rationale for postural drainage rests on the assumption that additional gravitational forces will enhance mucus transport from more or less vertically positioned bronchi. Different positions are described for the large bronchi [60]. In an animal study, CHOPRA et al. [11] found an increase in tracheal mucus transport velocity during postural drainage. Some studies have found improved mucus transport in patients with $\mathrm{CF}[61,62]$, but in a study in patients with COPD, no improvement was observed [63]. The effect of posture has also been investigated using pulmonary function tests and arterial blood gas analysis [64-67] without a clear demonstration of benefit. Changes in pulmonary function and gas exchange may not be the result of changes in mucus transport, but of changes in lung volume and ventilation-perfusion matching. Positioning can also place the patient at risk for gastro-oesophageal reflux [68], especially if there is pulmonary hyperinflation.

\section{Forced expirations and coughing}

High intrapulmonary pressures develop when the glottis is closed and there is an explosive burst of airflow, a cough, after glottic opening. During forced exhalation, also called "huffing", a forced expiratory manoeuvre is performed with an open glottis. Forced expiration combined with breathing control (diaphragmatic breathing), is known as FET, and the FET combined with thoracic expansion exercise is known as ACBT [60]. However these terms are not used consistently in the literature.

Transport of a viscoelastic gel through a tube can be augmented by sufficiently high airflow or two-phase gasliquid flow $[69,70]$. Mucus transport by two-phase gasliquid flow can occur both in an airway closed by mucus and in an open airway thickly lined with mucus. Mucus transport in a closed airway can only be achieved during forced expiration from high pressure leading to high airflow. Mucus transport in an open airway can be achieved by expiratory airflow during forced expiration, as well as by tidal breathing [71-73]. Mucus is mobilized both with 
expiratory airflow velocities of $1.0-2.5 \mathrm{~m} \cdot \mathrm{s}^{-1}$ (annular flow) or at flow velocities $>2.5 \mathrm{~m} \cdot \mathrm{s}^{-1}$ (misty flow) [69].

High-flow velocity is reached when airflow is high and the airway diameter is small. The effective airway diameter depends on the airway cross-sectional diameter, the thickness of the mucus layer, and the amount of dynamic compression of the airway. Airways are compressed during a forced expiration due to an increased transmural pressure. Compression primarily occurs in the central airways and this contributes to the development of local high airflow velocities in these airways. Forced expiration and coughing are probably the most effective manoeuvres in chest physiotherapy for improving mucus transport [30, 74-76]. When the force of the expiratory muscles is reduced leading to lower pleural pressures during coughing, dynamic compression of the airways is possibly less pronounced and can limit the effectiveness of coughing [77]. In these circumstances, the expiration can be assisted by manual compression of the thorax and the abdomen [78]. In some pathological conditions, smooth muscle contraction, inflammatory processes including oedema, and dynamic compression of the airways, can all reduce the diameter of the peripheral airways, limiting airflow and airflow velocity in the more central airways. In patients with decreased pulmonary elastic recoil pressure and airway collapse, the effectiveness of mucus transport by forced expiration is reduced [2]. ZACH et al. [79] found evidence that in patients with CF, the use of bronchodilators may decrease the stability of the airway walls and thus reduce the effectiveness of forced expiration and coughing because of airway collapse. This could not, however be confirmed in a recent study by Desmond et al. [80]. BENNETT et al. [81] found that mucus clearance by cough in patients with COPD was decreased after inhalation of ipratropium bromide and they speculated that this was due to alteration of the airway compression, or to changes in the rheological properties of the mucus.

During a forced expiration, high expiratory flows are built up in the first $0.1 \mathrm{~s}$ producing a high shear rate. High shear rates cause a reduction of the mucus viscosity. Repeated forced expiratory flows are therefore also thought to improve mucociliary transport by a temporary reduction of the viscosity of the mucus. Another potential mechanism is that repeated forced expirations with short intervals reduce the dwell time and thereby, temporarily, the adhesiveness of mucus to the bronchial wall. These hypotheses are supported by a study demonstrating that in an experimental model, transport of a mucus gel simulant in an artificial trachea was higher when the interval between the coughs was reduced [82]. No studies were performed on the effect of breathing exercises during tidal breathing on mucus transport, although from a theoretical point of view this is a possible mechanism to improve mucus transport.

\section{Evaluation of chest physiotherapy}

\section{Mucus transport assessment}

Transport rates of mucus in the human airways can be assessed by timing the transport rate of a tracer deposited on the bronchial mucus layer [83]. There are three different types of tracers used.
In the first type a bolus of a tracer, usually Teflon $(\mathrm{R}$ discs or albumin microspheres, is deposited on the large airways through a bronchoscope or by inhalation. The transport of the tracer is visualized by bronchoscopy, radiography or scintigraphy if radiolabelled particles are used. With bronchoscopic particle deposition, airway cilia can be damaged, disturbing mucociliary transport. Measurements of mucus transport rates using this technique are limited to local measurements in the large airways.

Alternatively, a radiopaque dust, usually tantalum powder [84] is blown into the lungs through an endotracheal tube, and deposition and clearance of the tracer is monitored radiographically. The amount of tantalum remaining in the lungs after a given time interval is scored visually and is expressed as a percentage of the initial amount. This technique is invasive, can damage the airways, and uses a relatively high radiation dose depending on the number of chest radiographs. Therefore, this technique is rarely used for measuring mucus transport.

Finally, a radioactive aerosol tracer (RAT) is inhaled and deposited on the airway surfaces. The amount of radioactive tracer is counted using a gamma camera or scintillation counters. Transport of the tracer is expressed as the percentage retention or the percentage decrease of the initial amount of radioactivity in defined regions of the lungs after a fixed time. This technique is one of the most reliable methods to measure mucus transport over a short period of time in the bronchial tree.

The radioactivity of the particles does not appear to influence mucus transport [85]. Deposition of the tracer is the principal factor that influences mucus clearance measurements [86]. Deposition of particles of a size $>0.5 \mu \mathrm{m}$ mass median aerodynamic diameter (MMAD) takes place via inertial impaction and gravitational sedimentation, with smaller particles being deposited due to Brownian diffusion [87]. The site of deposition of an aerosol in the bronchial tree depends on the inspiratory manoeuvre and the characteristics of the aerosol. The depth of the deposition is inversely related to the inspiratory flow rate $[88,89]$ with high inspiratory flow increasing central deposition. Whole lung deposition also increases when a breath-holding pause after inspiration is included [86].

To control the deposition pattern, monodisperse aerosols are used. These are usually produced by a spinning disc aerosol generator [90], and have an MMAD of 1.0-5.0 $\mu \mathrm{m}$ and a geometric standard deviation (ratio of $84.1 \%$ cumulative size to $50 \%$ cumulative size) $<1.22 \mu \mathrm{m}$.

Heterodisperse aerosols can be generated by jet nebulizers and have an MMAD between 1.0-5.0 $\mu \mathrm{m}$ with a geometric standard deviation between $1.7-2.0 \mu \mathrm{m}[91,92$. The main characteristic of the aerosol that influences the deposition pattern of monodisperse as well as heterodisperse aerosols is the MMAD [93]. The particle deposition patterns of a heterodisperse and a monodisperse aerosol with the same MMAD are similar [94]. Particle size influences the deposition pattern but does not affect mucus transport [95].

The amount of radioactivity deposited on the airway surface after inhalation of the aerosol is recorded with a gamma camera or by scintillation counters. Using a gamma camera for recording the radioactivity has the disadvantage that relatively more radioactivity is necessary, but the advantages are that the initial deposition pattern can be visualized, corrections can be made for deposition in the 
oesophagus or stomach, and that it permits recording of radioactivity in different regions of interest, allowing quantification of the initial deposition pattern and an estimation of the regional clearance. Assessment of the regional clearance is limited because only two-dimensional pictures can be obtained. The initial deposition pattern can be estimated by calculating the penetration index. To define the outer regions of the lungs and to correct for the lung volume, an 81 Krypton ventilation image or a transmission scan can be recorded. The penetration index is the ratio of the radioactivity from the radioaerosol in the peripheral to the central region divided by the ratio of the 81 Krypton ventilation radioactivity of the peripheral to the central region [96].

Clearance of the radioactive tracer, reflecting mucus transport can be expressed as the percentage retention or percentage decrease after a fixed period or as the area under the retention curve (AUC). Expressing clearance as the AUC reflects clearance, during the whole observation period. Clearance expressed as the percentage retention or as the percentage decrease after a certain time may also give information about clearance at different time intervals during the observation period. Clearance data are corrected for alveolar deposition by subtracting the amount of radioactive tracer deposited in the alveoli from the amount of whole lung deposition. To estimate the alveolar deposition, the amount of radioactive tracer is measured $24 \mathrm{~h}$ after inhalation. Correction for alveolar deposition may be useful in healthy subjects where some particles are deposited in the alveoli, but is less important in patients with obstructive pulmonary disease leading to a more central deposition of particles owing to impaction [97-99]. Correction for alveolar deposition with this technique may not always be valid, as retention after $24 \mathrm{~h}$ can also reflect bronchial deposition, especially when there is decreased mucus transport $[100,101]$.

Reproducibility of the RAT technique has been investigated by measuring the AUC $6 \mathrm{~h}$ after inhalation of the tracer in healthy subjects, asymptomatic smokers, asthmatics, patients with chronic bronchitis and patients with bronchiectasis [98]. This study found an intersubject coefficient of variation of $13 \%$ for the healthy subjects and $28-39 \%$ for the other groups. The intrasubject coefficient of variation was about half these values. REGNIS et al. [89] found in a small group of CF patients a lower intrasubject coefficient of variation of $3.3 \%$, as a result of controlling the mean inspiratory flow rate. In intervention studies, a cross-over design in which the subjects are their own controls is probably the best option.

There are preliminary data that mucus clearance assessed by the RAT technique may have systematic variations. MORTENSEN et al. [86] demonstrated that mucus transport is slower in males than in females, and slower in the summer than in the winter period. However, RUBIN and coworkers $[102,103]$ have demonstrated that tracheal mucus velocity in dogs and mucociliary clearance on the frog palate are more rapid in the summer. This makes more sense as increased panting would increase clearance and increased temperature would increase ciliary beat frequency and reduce apparent viscosity of the secretion.

It may be expected that the straightforward measurement of expectorated sputum volume would be an accurate method to assess the effectiveness of therapeutic interventions directed toward improving mucus clearance. How- ever, sputum volume measurements can be inaccurate because of patient reticence to expectorate, inadvertent swallowing of secretions, and salivary contamination of the secretions expectorated. The actual volume of secretions expectorated is extremely variable from day to day and even at different times of the day, with greater volumes generally being produced in the early morning. Finally, increased volumes of collected secretions could represent increased production of mucus as well as increased clearance. Measurement of a volume of expectorated mucus can give a global impression of transport assuming that mucus production in the airways is stable during the time of the measurements. Measurement of the volume of expectorated mucus is, in absolute terms, probably only reliable using the technique described by TOREMALM [104]. In this technique, two electrodes are located in the trachea or the canula in patients with a tracheostomy. Mucus is transported to the trachea were it closes the electrical circuit, by connecting the two electrodes, and starts a suction apparatus, which removes the mucus from the trachea. Removing the mucus opens the electrical circuit and consequently the suction apparatus stops.

Measurement of the volume of expectorated mucus has been used to investigate relative changes in mucus transport. Care should be taken that as little saliva as possible is mixed with the mucus and that as little mucus as possible is swallowed. Contamination with saliva can be partially corrected by drying the mucus and taking the dry weight for analysis. However, interventions that stimulate mucus secretion can change the hydration of expectorated secretions by $>50 \%$, making wet-to-dry weight calculations of expectorant invalid. Correlation between the volume of expectorated mucus and data obtained by the RAT technique is poor but statistically significant $(\mathrm{r}=0.39$, $\mathrm{p}<0.05$ ) [105] probably because data obtained using the RAT technique are independent of the volume of mucus. There is no difference in the transport rate of a tracer deposited on a thick mucus layer or on a thin mucus layer. This is supported by results from a study [105] demonstrating that the correlation between the radioactive tracer content in the expectorated mucus and the RAT clearance data was much better $(\mathrm{r}=0.78, \mathrm{p}<0.001)$.

In most studies investigating the effect of a physiotherapeutic intervention, the results of mucus transport measured by the RAT technique are checked by weighing the quantity of expectorated mucus. In table 1, the results of several studies are summarized. In most studies, an improvement in mucus transport quantified by the RAT technique was associated with an improvement in mucus transport quantified by the volume of expectorated mucus. Exceptions are the studies of SuTton et al. [14, 37], and HasANi et al. [110]. SutTON et al. [14, 37] found that mucus transport assessed by the RAT technique was not improved, although the volume of expectorated mucus was increased after chest physiotherapy. A possible explanation for this conflicting result may be that mucus in the peripheral airways was poorly labelled with the radioactive tracer and was therefore not reflected in the RAT data but only in the volume of expectorated mucus. This hypothesis is supported by the fact that a tracer tends to deposit inhomogeneously and more centrally so that with severe airway obstruction the tracer does not reach poorly ventilated parts of the lungs. HASANI et al. [110] found that coughing and forced expirations in patients 
Table 1. - Association between changes in mucus transport, owing to physiotherapeutic intervention, as assessed by the radioactive aerosol tracer (RAT) technique and the expectoration of mucus

\begin{tabular}{|c|c|c|}
\hline First author [ref] & RAT clearance & Mucus expectorated \\
\hline Pavia [36] & - & - \\
\hline BATEMAN [12] & + & + \\
\hline BATEMAN [13] & + & + \\
\hline Rossman [15] & + & + \\
\hline SutTon [14] & + & + \\
\hline SutTON [14] & - & + \\
\hline SutTON [37] & - & + \\
\hline VAN Hengstum [74] & - & - \\
\hline SutTon [106] & + & + \\
\hline VAN HeNGSTUM [107] & + & + \\
\hline VAN HengStum [50] & + & + \\
\hline MORTENSEN [105] & + & + \\
\hline CONWAY [108] & + & + \\
\hline HASANI [109] & + & - \\
\hline
\end{tabular}

Findings are independent from type of disease or type of physiotherapy. +: improvement, $\mathrm{p}<0.05$; -: no change, $\mathrm{p}>0.05$.

who did not expectorate mucus resulted in an improved mucus transport as quantified by the RAT technique.

The RAT technique is more sensitive than assessing the volume of expectorated mucus to quantify changes in bronchial mucus transport, especially when mucus production is low. A combination of measurement of mucus transport using the RAT technique and measurement of the volume of expectorated mucus is probably the most reliable method to quantify acute changes in mucus transport.

\section{Assessment of subjective effects associated with mucus retention}

An important but often overlooked aspect of sputum expectoration is the subjective experience of the patient. One of the potential effects of chest physiotherapy is to make expectoration more efficient or less tiring, or to concentrate expectoration over specific periods of the day. For the patient, these effects can be very important but are not measured by the methods described above. To the best of the authors' knowledge, no studies have been performed to investigate these potential effects of chest physiotherapy. The instruments that may be valuable are the "Questionnaire for ease of cough and sputum clearance" developed by Pетту et al. [111], and the St George's Respiratory Disease questionnaire [112]. The first questionnaire quantifies the subjective difficulty, frequency, and severity of cough and expectoration. The second is used to quantify the health-related quality of life including symptoms such as cough and sputum. The use of scoring systems developed to measure dyspnoea are of very limited value in assessing mucus mobilization, as significant dyspnoea is rarely a problem in patients with mild-to-moderate obstructive lung disease who are most likely to benefit from chest physiotherapy.

\section{Pulmonary function assessment}

It has often been assumed that mucus has a measurable effect on pulmonary function and that improvement of mucus transport will improve pulmonary function. Retention of mucus can theoretically reduce airway diameter and contribute to airflow obstruction. Therefore, in many studies, pulmonary function and particularly spirometry, have been used to evaluate the effect of airway clearance interventions meant to improve mucus transport. However, the measurement of airflow and simple lung volumes do not appear to reflect changes in mucus transport and are relatively insensitive to airway clearance manoeuvres.

Mucus can also completely obstruct some airways and thus influence static lung volumes and the volume of trapped gas. Decreased alveolar ventilation can lead to hypoxaemia. These effects can be different in different pulmonary diseases. The effects of sputum on pulmonary function were investigated by COCHRANE et al. [19] before and after the application of chest physiotherapy and it was found that specific conductance ( $\mathrm{s} G \mathrm{aw}$ ) was reduced without a significant change in FEV1 after chest physiotherapy. The improvement in $s G$ aw was not related to the volume of mucus expectorated. These authors speculated that redistribution of mucus throughout the airways as a result of chest physiotherapy, was responsible for the reduction in sGaw. REGNIS et al. [89] found in CF patients a significant correlation between mucus transport assessed with the RAT technique and lung function (RV/ TLC, $r=-0.39$ ) and with clinical score (National Institutes of Health (NIH), $r=0.39$ ). The relatively low correlation coefficients make it unlikely that changes in mucus transport owing to intervention affect pulmonary function or clinical score. Improved pulmonary function associated with an improvement of mucus transport or mucus expectoration has not been confirmed by other investigators. Table 2 gives an overview of studies in which an improvement of mucus transport, quantified by the RAT technique or by the amount of expectorated mucus, was related to a physiotherapeutic intervention as well as any concomitant changes in pulmonary function. It is clear that improvement in mucus transport is not necessarily reflected by an improved pulmonary function. Therefore, spirometry alone should not be used to evaluate changes in bronchial mucus transport.

Chest physiotherapy may affect other factors including ventilation-perfusion distribution $[32,54]$, breathing pattern [114], and smooth muscle tone [18]. These changes will bias pulmonary function test results and may mask an effect of improved mucus transport on pulmonary function. Chest physiotherapy can lead to an improved [54] or decreased [32] ventilation-perfusion matching. In patients with pulmonary disease there can be a considerable circadian variation in pulmonary function [115]. Careful control measurements considering this are essential. Postural changes can also have either positive or negative effects on pulmonary function and gas exchange $[58,59$, 64-67].

It is important to assess the effect of physiotherapy on pulmonary function to evaluate side-effects secondary to the intervention or to test the theoretical basis on which a certain intervention is based [116]. Testing the rate of change in pulmonary function over time may also be worthwhile to investigate the long-term effects of chest physiotherapy on the course of the disease.

Spirometry is neither sensitive nor specific in assessing immediate changes in mucus transport. The study of REGNIs et al. [89] suggests that measurements of gas trapping, e.g. RV/TLC ratio, may better reflect mucus transport than measurement of FVC or FEV1. Evaluation of chest 
Table 2. - Association between an improvement in mucus transport owing to a physiotherapeutic intervention, as assesed by changes in pulmonary function

\begin{tabular}{|c|c|c|c|c|}
\hline First author [ref] & Diagnosis & Patients $n$ & Pulmonary function variables & Effect \\
\hline COCHRANE [19] & COPD & 23 & sGaw, FEV1 &,+- \\
\hline OLDENBURG [63] & COPD & 8 & FEV 1, FVC & - \\
\hline MAY [52] & COPD & 35 & FEV1, PEF, FEF50\%, FEF75\%, FVC & - \\
\hline MALONEY [9] & COPD & 13 & sGaw, FEV1, FEF25-75\%, FVC, VC, VTG & - \\
\hline Mazzocco [29] & Bronchiectasis & 13 & FEV 1, PEF, FVC & - \\
\hline GALLON [51] & Mixed group & 9 & FEV1, PEF, FEF25-75\%, FVC & - \\
\hline VAN HENGSTUM [113] & COPD & 8 & sGaw, FEV1, FEF25-75\%, FVC & - \\
\hline SutTon $[106]$ & Bronchiectasis & 8 & FEV 1, FVC & - \\
\hline VAN HeNGStum [50] & COPD & 8 & sGaw, FEV1, MEF50\%, FVC & - \\
\hline
\end{tabular}

COPD: chronic obstructive pulmonary disease; sGaw: specific airway conductance; FEV1: forced expiratory volume in one second; FVC: forced vital capacity; PEF: peak expiratory flow; FEF50\%: forced expiratory flow at 50\% of FVC; FEF $75 \%$ : FEF at $75 \%$ of FVC; FEF25-75\%: forced mid expiratory flow; MEF50\%: mean maximal expiratory flow; VC: vital capacity; VTG: volume thoracic gas. +: improvement, $\mathrm{p}<0.05 ;-$ : no change $\mathrm{p}>0.05$.

physiotherapy only with pulmonary function tests in short-term studies seems to be inadequate. The popularity of using pulmonary function tests is probably based more on the availability of the instruments than on a theoretical basis related to the question of chest physiotherapy improving mucus transport.

\section{Hospitalization}

Improvement of bronchial mucus transport is thought to reduce the retention of infected secretions and thus the frequency of respiratory tract infections [117]. In patients with CF, the application of chest physiotherapy is thought to contribute to increased longevity. There are difficult ethical problems in evaluating these effects as an intervention that has been shown to have short-term beneficial effects on mucus transport cannot be ethically withheld from patients. REISMAN et al. [118] compared FET and "conventional chest physiotherapy" in patients with CF. No differences were found in hospitalization for pulmonary exacerbation or pulmonary function. There were also two long-term studies investigating the effect of PEEP breathing physiotherapy $[119,120]$. The results of these two studies are conflicting in terms of exacerbation frequency and antibiotic use.

\section{Quality of life}

Hypersecretion, reduced mucus transport, and airflow obstruction are impairments, while chronic coughing and expectoration of mucus or dyspnoea can limit the patient in daily or recreational activities, and can therefore be classified as disabilities. Chronic coughing, expectoration and dyspnoea can also limit the patient in their social functioning and thus lead to a handicap. The effects of intervention can also be evaluated in these terms. Most studies have focused on effects on impairment level such as mucus transport and pulmonary function. Interventions should also evaluate changes in the disability level, e.g. subjective experience of coughing and activities of daily living, and on handicap level using quality-of-life questionnaires. However, an intervention may be effective on impairment level by improving bronchial mucus transport, but may have negative effects on disability or handicap level due to the dependence on another person or a complicated device. There are limited data concerning the psychological and social aspects of chest physiotherapy. Newton and Bevans [21] investigated the short-term effect of chest physiotherapy on daily eating score, sleep score, and a Medical Research Council (MRC) chronic bronchitis questionnaire and found no improvement. Chest physiotherapy, like other physiotherapeutic interventions, is not a medication prescribed by a physician, but a social interaction between the therapist and the patient, often over a number of years. Research evaluating changes in mucus transport can potentially be based on this phenomenological paradigm [121]. For example, it may be worthwhile investigating the qualitative effects of an intervention on expectoration, social contacts, and quality of life. The outcome of these studies cannot be interpreted in terms of improvement of mucus transport, but questions concerning qualitative aspects can be particularly important when different interventions are equally effective in improving mucus transport.

Efficacy studies should be performed in homogeneous groups of patients with well-described characteristics in terms of age, sex, diagnosis, baseline pulmonary function tests, and, if possible, compliance characteristics. The effects of chest physiotherapy are probably determined by special characteristics of subgroups, characterized by lung mechanics, bronchial hyperreactivity, rheological properties of mucus, and localization of mucus in the bronchial tree. Further studies are needed to identify the important subgroups. An adequate description of the intervention is essential, as just calling an intervention "routine chest physiotherapy" is both insufficient and confusing. Postural drainage is sometimes used for a combination of techniques, including percussion and vibration, forced expiration and coughing.

Publications should describe the intervention in terms that include duration, repetitions, dose, frequency, number of physiotherapists involved, and a description of the technique. Care should be taken that control groups and control measurements are comparable. The fact that the effect of mucus retention is poorly understood implies that in studies investigating the effect of improving mucus transport, more than one outcome variable should be used in order to cover different potential effects. 


\section{References}

1. Aikawa T, Shimura S, Sasaki H, Takishima T, Yaegashi $\mathrm{H}$, Takahashi T. Morphometric analysis of intraluminal mucus in airways in chronic obstructive pulmonary disease. Am Rev Respir Dis 1989; 140: 477-482.

2. van der Schans CP, Piers DA, Beekhuis H, Koeter GH, van der Mark TW, Postma DS. Effect of forced expirations on mucus clearance in patients with chronic airflow obstruction: effect of lung recoil pressure. Thorax 1990; 45: 623-627.

3. Mullen JB, Wright JL, Wiggs BR, Pare PD, Hogg JC. Structure of central airways in current smokers and exsmokers with and without mucus hypersecretion: relation to lung function. Thorax $1987 ; 42$ : 843-848.

4. Vestbo J, Prescott E, Lange P. Association of chronic mucus hypersecretion with FEV1 decline and chronic obstructive pulmonary disease morbidity. Copenhagen City Heart Study Group. Am J Respir Crit Care Med 1996; 153: 1530-1535.

5. Prescott E, Lange P, Vestbo J. Chronic mucus hypersecretion in COPD and death from pulmonary infection. Eur Respir $J$ 1995; 8: 1333-1338.

6. King M, Kelly S, Cosio M. Alteration of airway reactivity by mucus. Respir Physiol 1985; 62: 47-59.

7. Clarke SW. Management of mucus hypersecretion. Eur J Respir Dis Suppl 1987; 153: 136-144.

8. Mackenzie CF. History and literature review of chest physiotherapy, chest physiotherapy program, patient population and respiratory care at MIEMSS. In: Mackenzie CF, Ciesla N, Imle PC, Klemic N, eds. Chest Physiotherapy in the Intensive Care Unit. Baltimore, Williams and Wilkins, 1981; pp. 1-25.

9. Maloney FP, Fernandez E, Hudgel DW. Postural drainage effects after bronchodilator inhalation in patients with chronic airway obstruction. Arch Phys Med Rehabil 1981; 62: 452-455.

10. Selsby DS. Chest physiotherapy. BMJ 1989; 52: 541-542.

11. Chopra SK, Taplin GV, Simmons DH, Robinson GD Jr., Elam D, Coulson A. Effects of hydration and physical therapy on tracheal transport velocity. Am Rev Respir Dis 1977; 115: 1009-1014.

12. Bateman JR, Newman SP, Daunt KM, Pavia D, Clarke SW. Regional lung clearance of excessive bronchial secretions during chest physiotherapy in patients with stable chronic airways obstruction. Lancet 1979; 1: 294-297.

13. Bateman JR, Newman SP, Daunt KM, Sheahan NF, Pavia $\mathrm{D}$, Clarke SW. Is cough as effective as chest physiotherapy in the removal of excessive tracheobronchial secretions? Thorax 1981; 36: 683-687.

14. Sutton PP, Parker RA, Webber BA, et al. Assessment of the forced expiration technique, postural drainage and directed coughing in chest physiotherapy. Eur $J$ Respir Dis 1983; 64: 62-68.

15. Rossman CM, Waldes R, Sampson D, Newhouse MT. Effect of chest physiotherapy on the removal of mucus in patients with cystic fibrosis. Am Rev Respir Dis 1982; 126: $131-135$

16. Anthonisen P, Riis P, Sogaard-Andersen T. The value of lung physiotherapy in the treatment of acute exacerbations in chronic bronchitis. Acta Med Scand 1964; 175: 715-719.

17. Tecklin JS, Holsclaw DS. Evaluation of bronchial drainage in patients with cystic fibrosis. Phys Ther 1975; 55: 1081-1084.

18. Campbell AH, O'Connell JM, Wilson F. The effect of chest physiotherapy upon the FEV1 in chronic bronchitis. Med J Aust 1975; 1: 33-35.

19. Cochrane GM, Webber BA, Clarke SW. Effects of sputum on pulmonary function. $B M J 1977 ; 2$ : 1181-1183.
20. Newton DA, Stephenson A. Effect of physiotherapy on pulmonary function. A laboratory study. Lancet 1978; 2: 228-229.

21. Newton DA, Bevans HG. Physiotherapy and intermittent positive-pressure ventilation of chronic bronchitis. $B M J$ 1978; 2: 1525-1528.

22. Graham WG, Bradley DA. Efficacy of chest physiotherapy and intermittent positive-pressure breathing in the resolution of pneumonia. N Engl J Med 1978; 199: 624-627.

23. Feldman J, Traver GA, Taussig LM. Maximal expiratory flows after postural drainage. Am Rev Respir Dis 1979; 119: 239-245.

24. Weller PH, Bush E, Preece MA, Matthew DJ. Shortterm effects of chest physiotherapy on pulmonary function in children with cystic fibrosis. Respiration 1980; 40: 53-56.

25. Zapletal A, Stefanova J, Horak J, Vavrova V, Samanek M. Chest physiotherapy and airway obstruction in patients with cystic fibrosis - a negative report. Eur J Respir Dis 1983; 64: 426-433.

26. Desmond KJ, Schwenk WF, Thomas E, Beaudry PH, Coates AL. Immediate and long-term effects of chest physiotherapy in patients with cystic fibrosis. $J$ Paediatr 1983; 103: 538-542.

27. de Boeck C, Zinman R. Cough versus chest physiotherapy. A comparison of the acute effects on pulmonary function in patients with cystic fibrosis. Am Rev Respir Dis 1984; 129: 182-184.

28. Mohsenifar Z, Rosenberg N, Goldberg HS, Koerner SK. Mechanical vibration and conventional chest physiotherapy in outpatients with stable chronic obstructive lung disease. Chest 1985; 87: 483-485.

29. Mazzocco MC, Owens GR, Kirilloff LH, Rogers RM. Chest percussion and postural drainage in patients with bronchiectasis. Chest 1985; 88: 360-363.

30. Webber BA, Hofmeir JL, Morgan MD, Hodson ME. Effects of postural drainage, incorporating the forced expiration technique, on pulmonary function in cystic fibrosis. Br J Dis Chest 1986; 80: 353-359.

31. Bain J, Bishop J, Olinsky A. Evaluation of directed coughing in cystic fibrosis. Br J Dis Chest 1988; 82: 138-148.

32. Connors AF, Hammon WE, Martin RJ, Rogers RM. Chest physical therapy. The immediate effect on oxygenation in acutely ill patients. Chest 1980; 78: 559-564.

33. March H. Appraisal of postural drainage for chronic obstructive pulmonary disease. Arch Phys Med Rehabil 1971; 52: 528-530.

34. Kerrebijn KF, Veentjer R, Bonzet-van de Water E. The immediate effect of physiotherapy and aerosol treatment on pulmonary function in children with cystic fibrosis. Eur J Respir Dis 1982; 63: 35-42.

35. Britton S, Bejstedt M, Vedin L. Chest physiotherapy in primary pneumonia. BMJ (Clin Res Ed) 1985; 290: 17031704.

36. Pavia D, Thompson ML, Phillipakos D. A preliminary study of the effect of a vibrating pad on bronchial clearance. Am Rev Respir Dis 1985; 113: 92-96.

37. Sutton PP, Lopez Vidriero MT, Pavia D, et al. Assessment of percussion, vibratory-shaking and breathing exercises in chest physiotherapy. Eur J Respir Dis 1985; 66: 147-152.

38. van der Schans CP, Piers DA, Postma DS. Effect of manual percussion on tracheobronchial clearance in patients with chronic airflow obstruction and excessive tracheobronchial secretion. Thorax 1986; 41: 448-452.

39. King M, Phillips DM, Gross D, Vartian V, Chang HK, Zidulka A. Enhanced tracheal mucus clearance with high frequency chest wall compression. Am Rev Respir Dis 1983; 128: 511-515.

40. Rubin EM, Scantlen GE, Chapman GA, Eldridge M, Menendez R, Wanner A. Effect of chest wall oscillation 
on mucus clearance: comparison of two vibrators. Pediatr Pulmonol 1989; 6: 122-126.

41. Chang HK, Weber ME, King M. Mucus transport by high-frequency nonsymmetrical airflow. J Appl Physiol 1988; 65: 1203-1209.

42. Flower KA, Eden RI, Lomax L, Mann NM, Burgess J. New mechanical aid to physiotherapy in cystic fibrosis. BMJ 1979; 2: 630-631.

43. Radford R, Barutt J, Billingsley JG, Hill W, Lawson WH, Willich WA. A rational basis for percussion-augmented mucociliary clearance. Respir Care 1982; 27: 556-563.

44. George RJ, Johnson MA, Pavia D, Agnew JE, Clarke SW, Geddes DM. Increase in mucocillary clearance in normal man induced by oral high frequency oscillation. Thorax 1985; 40: 433-437.

45. Gross D, Zidulka A, O'Brien C, et al. Peripheral mucociliary clearance with high-frequency chest wall compression. J Appl Physiol 1985; 58: 1157-1163.

46. King M, Phillips DM, Zidulka A, Chang HK. Tracheal mucus clearance in high-frequency oscillation. II: chest wall versus mouth oscillation. Am Rev Respir Dis 1984; 130: 703-706.

47. King M, Zidulka A, Phillips DM, Wight D, Gross D, Chang HK. Tracheal mucus clearance in high-frequency oscillation: effect of peak flow rate bias. Eur Respir $J$ 1990; 3: 6-13

48. Freitag L, Long WM, Kim CS, Wanner A. Removal of excessive bronchial secretions by asymmetric high-frequency oscillations. J Appl Physiol 1989; 67: 614-619.

49. Pryor JA, Parker RA, Webber BA. A comparison of mechanical and manual percussion as adjuncts to postural drainage in the treatment of cystic fibrosis in adolescents and adults. Phys Ther 1981; 67: 140-141.

50. van Hengstum M, Festen J, Beurskens C, Hankel M, van den Broek W, Corstens F. No effect of oral high frequency oscillation combined with forced expiration manoeuvres on tracheobronchial clearance in chronic bronchitis. Eur Respir J 1990; 3: 14-18.

51. Gallon A. Evaluation of chest percussion in the treatment of patients with copious sputum production. Respir Med 1991; 85: 45-51.

52. May DB, Munt PW. Physiologic effects of chest percussion and postural drainage in patients with stable chronic bronchitis. Chest 1979; 75: 29-32.

53. Scherer TA, Barandun J, Martinez E, Wanner A, Rubin EM. Effect of high-frequency oral airway and chest wall oscillation and conventional chest physical therapy on expectoration in patients with stable cystic fibrosis. Chest 1998; 113: 1019-1027.

54. Holody B, Goldberg HS. The effect of mechanical vibration physiotherapy on arterial oxygenation in acutely ill patients with atelectasis or pneumonia. Am Rev Respir Dis 1981; 124: 372-375.

55. Piquet J, Brochard L, Isabey $\mathrm{D}$, et al. High frequency chest wall oscillation in patients with chronic air-flow obstruction. Am Rev Respir Dis 1987; 136: 1355-1359.

56. Warwick WJ, Hansen LG. The long-term effect of highfrequency chest compression therapy on pulmonary complications of cystic fibrosis. Pediatr Pulmonol 1991; 11: 265-271.

57. Arens R, Gozal D, Omlin KJ, et al. Comparison of high frequency chest compression and conventional chest physiotherapy in hospitalized patients with cystic fibrosis. Am J Respir Crit Care Med 1994; 150: 1154-1157.

58. Wollmer P, Ursing K, Midgren B, Eriksson L. Inefficiency of chest percussion in the physical therapy of chronic bronchitis. Eur J Respir Dis 1985; 66: 233-239.

59. Zidulka A, Chrome JF, Wight DW, Burnett S, Bonnier L, Fraser R. Clapping or percussion causes atelectasis in dogs and influences gas exchange. J Appl Physiol 1989; 66: $2833-2838$.
60. Webber BA, Pryor JA. Physiotherapy skills: techniques and adjuncts. In: Webber BA, Pryor JA, eds. Physiotherapy for Respiratory and Cardiac Problems. London, Churchill Livingstone, 1993; 113-171.

61. Wong JW, Keens TG, Wannamaker EM, et al. Effects of gravity on tracheal mucus transport rates in normal subjects and in patients with cystic fibrosis. Pediatrics 1977; 60: 146-152.

62. Verboon JM, Bakker W, Sterk PJ. The value of the forced expiration technique with and without postural drainage in adults with cystic fibrosis. Eur J Respir Dis 1986; 69: 169-174.

63. Oldenburg FA, Dolovich MB, Montgomery JM, Newhouse MT. Effects of postural drainage, exercise and cough on mucus clearance in chronic bronchitis. Am Rev Respir Dis 1979; 120: 730-745.

64. Dhainaut JF, Bons J, Bricard C, Monsallier JF. Improved oxygenation in patients with extensive unilateral pneumonia using the lateral decubitis position. Thorax 1980; 35: 792-793.

65. Gillespie DJ, Rehder K. Body position and ventilationperfusion relationships in unilateral pulmonary disease. Chest 1987; 92: 75-79.

66. Mahler DA, Snyder PE, Virgulto JA, Loke J. Positional dyspnea and oxygen desaturation related to carcinoma of the lung. Up with the good lung. Chest 1983; 83: 826827.

67. Chang SC, Chang HI, Shiao GM, Perng RP. Effect of body position on gas exchange in patients with unilateral central airway lesions. Down with the good lung? Chest 1993; 103: 787-791.

68. Button BM, Heine RG, Catto Smith AG, Phelan PD, Olinsky A. Postural drainage and gastro-oesophageal reflux in infants with cystic fibrosis. Arch Dis Child 1997; 76: $148-150$.

69. Clarke SW, Jones JG, Oliver DR. Resistance to two-phase gas-liquid flow in airways. J Appl Physiol 1970; 29: 464471.

70. Leith DE. Cough. Phys Ther 1968; 48: 439-447.

71. Kim CS, Rodriguez CR, Eldridge MA, Sackner MA. Criteria for mucus transport in the airways by two-phase gas-liquid flow mechanism. $J$ Appl Physiol 1986; 60: 901-907.

72. Kim CS, Iglesias AJ, Sackner MA. Mucus clearance by two-phase gas-liquid flow mechanism: asymmetric periodic flow model. J Appl Physiol 1987; 62: 959-971.

73. Sackner MA, Kim CS. Phasic flow mechanisms of mucus clearance. Eur J Respir Dis Suppl 1987; 153: 159-164.

74. van Hengstum M, Festen J, Beurskens C, Hankel M, Beekman F, Corstens F. Conventional physiotherapy and forced expiration manoeuvres have similar effects on tracheobronchial clearance. Eur Respir J 1988; 1: 758-761.

75. Pryor JA, Webber BA. An evaluation of the forced expiration technique as an adjunct to postural drainage. Phys Ther 1979; 65: 304-307.

76. Scherer PW. Mucus transport by cough. Chest 1981; 80: 830-833.

77. Arora NS, Gal TJ. Cough dynamics during progressive expiratory muscle weakness in healthy curanized subjects. J Appl Physiol 1981; 51: 494-498.

78. Bach JR, Smith WH, Michaels J, et al. Airway secretion clearance by mechanical exsuflation for post-poliomyelitis ventilator-assisted individuals. Arch Phys Med Rehabil 1993; 74: 170-177.

79. Zach MS, Oberwaldner B, Forche G, Polgar G. Bronchodilators increase airway stability in cystic fibrosis. Am Rev Respir Dis 1985; 131: 537-543.

80. Desmond KJ, Demizio DL, Allen PD, Macdonald ND, Coates AL. Effect of salbutamol on gas compression in 
cystic fibrosis and asthma. Am J Respir Crit Care Med 1994; 149: 673-677.

81. Bennett WD, Chapman WF, Mascarella JM. The acute effect of ipratropium bromide bronchodilator therapy on cough clearance in COPD. Chest 1993; 103: 488-495.

82. Zahm JM, King M, Duvivier C, Pierrot D, Girod S, Puchelle E. Role of simulated repetitive coughing in mucus clearance. Eur Respir J 1991; 4: 311-315.

83. Pavia D, Bateman JR, Sheahan NF, Agnew JE, Newman SP, Clarke SW. Techniques for measuring lung mucociliary clearance. Eur J Respir Dis Suppl 1980; 110: 157-177.

84. Nadel JA, Clarke SW. A new technique for studying airway deposition, morphology and mechanisms using powdered tantalum. Inhaled Part 1970; 1: 43-47.

85. Yeates DB, Pitt BR, Spektor DM, Karron GA, Albert RE. Coordination of mucociliary transport in human trachea and intrapulmonary airways. J Appl Physiol 1981; 51: 1057-1064.

86. Mortensen J, Groth S, Lange P. Characteristics of lung mucociliary clearance measurements in healthy subjects. Eur Respir J 1991; 4: 464 (Abstract)

87. Stuart BO. Deposition of inhaled aerosols. Arch Intern Med 1973; 131: 60-73

88. Pavia D, Thompson ML, Clarke SW, Shannon HS. Effect of lung function and mode of inhalation on penetration of aerosol into the human lung. Thorax 1977; 32: 194-197.

89. Regnis JA, Robinson M, Bailey DL, et al. Mucociliary clearance in patients with cystic fibrosis and in normal subjects. Am J Respir Crit Care Med 1994; 150: 66-71.

90. May KR. An improved spinning top homogeneous spray apparatus. J Appl Physiol 1949; 20: 932-938.

91. Stahlhofen W, Gebhart J, Heyder J, Scheuch G. Deposition pattern of droplets from medical nebulizers in the human respiratory tract. Bull Eur Physiopathol Respir 1983; 19: 459-463.

92. Sterk PJ, Plomp A, van de Vate JF, Quanjer PH. Physical properties of aerosols produced by several jet- and ultrasonic nebulizers. Bull Eur Physiopathol Respir 1984; 20: 65-72.

93. Newman SP. Deposition and Effects of Inhalation Aerosols. Lund, Sweden, AB Draco, 1983.

94. Morrow PE. An evaluation of the physical properties of monodisperse and heterodisperse aerosols used in the assessment of bronchial function. Chest 1981; 80: 809-813.

95. Ilowite JS, Smaldone GC, Perry RJ, Bennett WD, Foster WM. Relationship between tracheobronchial particle clearance rates and sites of initial deposition in man. Arch Environ Health 1989; 44: 267-273.

96. Agnew JE, Pavia D, Clarke SW. Airways penetration of inhaled radioaerosol: and index to small airways function? Eur J Respir Dis 1981; 62: 239-255.

97. Isawa T, Teshima T, Hirano T, Ebina A, Anazawa Y, Konno K. Effect of bronchodilation on the deposition and clearance of radioaerosol in bronchial asthma in remission. J Nucl Med 1987; 28: 1901-1906.

98. Thomson ML, Pavia D. Particle penetration and clearance in the human lung. Results in healthy subjects and subjects with chronic bronchitis. Arch Environ Health 1974; 29: 214-219.

99. Dolovich MB, Sanchis J, Rossman C, Newhouse MT. Aerosol penetrance: a sensitive index of peripheral airways obstruction. J Appl Physiol 1976; 40: 468-471.

100. Stahlhofen W, Gebhart J, Rudolf G, Scheuch G. Measurement of lung clearance with pulses of radioactivelylabelled aerosols. J Aerosol Sci 1986; 17: 333-336.

101. Wolff RK, Tillquist H, Muggenburg BA, Harkema JR, Mauderly JL. Deposition and clearance of radiolabelled particles from small ciliated airways in beagle dogs. $J$ Aerosol Sci 1989; 2: 261-270.

102. Rubin BK, Cheeseman CI, Gourishankar S, King M. Is there a seasonal variation in mucus transport and nutrient absoption in the leopard frog? Can J Physiol Pharmacol 1992; 70: 442-446.

103. King M, Rubin BK, Ramirez O, Zayas JG. Mucus velocity, water content and viscoelasticity in beagle trachea show seasonal variations. Chest 1990; 98: 67 (Abstract).

104. Toremalm NG. The daily amount of tracheo-bronchial secretion in man. Acta Otolaryngol 1960; 158: 43-53.

105. Mortensen J, Falk M, Groth S, Jensen C. The effects of postural drainage and positive expiratory pressure physiotherapy on tracheobronchial clearance in cystic fibrosis. Chest 1991; 100: 1350-1357.

106. Sutton PP, Gemmell HG, Innes N, et al. Use of nebulised saline and nebulised terbutaline as an adjunct to chest physiotherapy. Thorax 1988; 43: 57-60.

107. van Hengstum M, Festen J, Beurskens C, Hankel M, Beekman F, Corstens F. Effect of positive expiratory pressure mask physiotherapy (PEP) versus forced expiration technique (FET/PD) on regional lung clearance in chronic bronchitis. Eur Respir J 1991; 4: 651-654.

108. Conway JH, Fleming JS, Perring S, Holgate ST. Humidification as an adjunct to chest physiotherapy in aiding tracheo-bronchial clearance in patients with bronchiectasis. Respir Med 1992; 86: 109-114.

109. Hasani A, Pavia D, Agnew JE, Clarke SW. The effect of unproductive coughing/FET on regional mucus movement in the human lungs. Respir Med 1991; 85: Suppl. A, 23-26.

110. Hasani A, Pavia D, Agnew JE, Clarke SW. Regional mucus transport following unproductive cough and forced expiration technique in patients with airways obstruction. Chest 1994; 105: 1420-1425.

111. Petty TL. The National Mucolytic Study. Results of a randomized, double-blind, placebo-controlled study of iodinated glycerol in chronic obstructive bronchitis. Chest 1990; 97: 75-83.

112. Jones PW, Quirk FH, Baveystock CM, Littlejohns P. A self-complete measure of health status for chronic airflow limitation. The St. George's Repiratory Questionnaire. Am Rev Respir Dis 1992; 145: 1321-1327.

113. van Hengstum M, Festen J, Beurskens C, et al. The effect of positive expiratory pressure versus forced expirations technique on tracheobronchial clearance in chronic bronchitics. Scand J Gastroenterol Suppl 1988; 143: 114-118.

114. Bolser DC, Lindsey BG, Shannon R. Respiratory pattern changes produced by intercostal muscle/rib vibration. $J$ Appl Physiol 1988; 64: 2458-2462.

115. Postma SD, Keyzer JJ, Koeter GH, Sluiter HJ, De Vries $\mathrm{K}$. Influence of the parasympathetic and sympathetic nervous system on nocturnal bronchial obstruction. Clin Sci 1985; 69: 251-258.

116. van der Schans CP, van der Mark TW, de Vries G, et al. Effect of positive expiratory pressure breathing in patients with cystic fibrosis. Thorax 1991; 46: 252-256.

117. Zach MS, Oberwaldner B. Chest physiotherapy-the mechanical approach to antiinfective therapy in cystic fibrosis. Infection 1987; 15: 381-384.

118. Reisman JJ, Rivington Law B, Corey M, et al. Role of conventional physiotherapy in cystic fibrosis. $J$ Pediatr 1988; 113: 632-636.

119. Christensen EF, Nedergaard T, Dahl R. Long-term treatment of chronic bronchitis with positive expiratory pressure mask and chest physiotherapy. Chest 1990; 97: 645-650.

120. Chnistensen HR, Simonsen K, Lange P, et al. PEEP-mask in patients with severe obstructive pulmonary disease: a negative report. Eur Respir J 1990; 3: 267-272.

121. Shepard KF, Jensen GM, Schmoll BJ, Hack LM, Gwyer J. Alternative approaches to research in physical therapy: positivism and phenomenology. Phys Ther 1993; 73: 88-97. 